\title{
The impact of the information search variables, time pressure and involvement, on buying behaviour in a three-dimensional hypermedia computer-mediated environment
}

\author{
A.H. Nelmapius* \\ Nelson Mandela Metropolitan University \\ PO Box 77000, Port Elizabeth, 6031, Republic of South Africa \\ Albert.Nelmapius@nmmu.ac.za \\ C. Boshoff* \\ Department of Business Management, Nelson Mandela Metropolitan University \\ PO Box 77000, Port Elizabeth, 6031, Republic of South Africa \\ Christo.Boshoff@nmmu.ac.za \\ A.P. Calitz \\ Department of Computer Science and Information Systems, Nelson Mandela Metropolitan University \\ PO Box 77000, Port Elizabeth, 6031, Republic of South Africa \\ Andre.Calitz@nmmu.ac.za \\ B.R. Klemz \\ Department of Marketing, Winona State University, \\ Winona, United States of America \\ bklemz@winona.edu \\ Received September 2004
}

\begin{abstract}
The Internet has the potential (through enormous computing and data processing capabilities and the overcoming of the physical retail constraints of limited time and space) to change the way that modern-day business is being conducted. The potential of the Internet is, however, not always translated into actual retail sales.
\end{abstract}

\begin{abstract}
Currently product information on Web sites is mainly, with a few exceptions, of a two-dimensional nature. This study specifically investigates aspects of consumer behaviour within a three-dimensional hypermedia environment, as opposed to the two-dimensional environment. The role of a sub-set of consumer behaviour variables (time pressure and consumer involvement), as potential barriers to the more frequent use of a three-dimensional Computer-Mediated Environment $(\mathrm{CME})$ as an alternative retail-shopping environment, is empirically assessed.
\end{abstract}

In broad terms the objective of this study was to assess whether manipulating information availability in a CME environment influences consumers’ online shopping behaviour.

\begin{abstract}
The results show that there is a negative relationship between shopping time pressure on the one hand and the time spent shopping on the other hand, in an Internet shopping environment without price and information displays $(\mathrm{p}<0.05)$; an Internet shopping environment with only price displays $(\mathrm{p}<0,01)$ and an Internet shopping environment with only product information displays ( $\mathrm{p}<0,001$ ). There is, however, no relationship between time pressure and consumer involvement regardless of the information available to the Internet shopper.
\end{abstract}

*To whom all correspondence should be addressed.

\section{Introduction}

The goals of business firms, it has been established empirically, are to create wealth via profit-maximisation, maximising the rate of return on equity capital and the like (Bosch, 1982). Marketing as a business management function contributes to the realisation of these goals largely by the creation of utility, that is, the value being created by marketers by satisfying consumer needs that would not otherwise have been possible. For instance, marketers create place utility for consumers by making products available where they are needed and time utility by offering products and services when they are needed. Marketers also attempt to overcome the information gap by providing consumers with information on need-satisfying products through the use of, amongst others, advertising (information utility). By overcoming the separation gap and giving consumers the 
opportunity to use or consume products, marketers create possession utility.

Business firms, in their never-ending quest to be competitive, continuously explore new ways to enhance the utility they can offer to consumers (better products, lower prices, more convenient distribution) or increase their revenue (improved sales, growing market share, accessing new market segments etc.) or they explore new ways to reduce their costs. Electronic commerce and Internet marketing are often suggested as means of lowering marketing costs and particularly distribution and logistics costs (Hoffman \& Novak, 1996:51; Verity \& Hof in Hoffman \& Novak, 1996:51; Borchard, 1999).

There is sufficient anecdotal evidence (Alba, Lynch, Weitz, Janiszewski, Lutz, Sawyer \& Wood, 1997:41) that the use of the Internet can be of considerable value for the marketing function in their endeavours to contribute to the firm's strategic goals. If one considers that the marketing function's primary objective is to create exchanges that satisfy the individual consumer's and the firm's goals, the Internet, as promotional tool, has the potential to provide the individualised two-way communication required by many consumers, by combining interactivity and real-time publishing with enormous data collection capabilities. Marketers can use the Internet technology to attract consumers, to allow consumers to examine a firm's customised offerings, to initiate questions or discussions and to make a purchase with maximum comfort and convenience. In short, the Internet is a powerful tool that marketers may use to individualise their offerings and move closer to the ideal of one-on-one marketing.

It is, however, true that the rate of adoption of Internet retailing by consumers (business-to-consumer or B2C) has been slow and that Internet retail expenditure in South African is very low (World Wide Worx, 2002).

Given the potential benefits of Internet retailing for both consumers (24 hour access, convenience) and retailers (lower costs, reduced retail space) one has to contemplate the reasons for the slow rate of consumer adoption. One must consider, for instance, whether the electronic shopping environment is so much different from conventional retailing that consumers find it hard to make the switch from 'bricks and mortar' to 'clicks and sites'. More specifically, are conventional models of consumer behaviour valid for the new electronic shopping environment?

This study attempts to assess the relevance of a small component of conventional consumer behaviour models by considering the role of two information search variables (time pressure and consumer involvement) on buying behaviour in a three-dimensional hypermedia computermediated environment.

By assessing conventional consumer behaviour/buying behaviour variables in this new shopping environment it will be possible to initiate a critical review of such models to assess their applicability and relevance in the cyberspace shopping environment.

\section{The Internet as direct marketing channel}

Direct marketing can take the form of catalogue marketing, direct mail, telemarketing, and electronic shopping or interactive home shopping (IHS). Examples of IHS shopping include shopping in a Computer Mediated Environment (CME), telephone banking and more recently TV-shopping through Digital Satellite Television (DSTV). The prevailing CME, the Internet, of which the World Wide Web (WWW) is the current implementation, as new marketing medium has the potential to radically change the way firms conduct business with their customers by facilitating interactive multimedia many-to-many communication with consumers (Hoffman \& Novak, 1996:50) and in this way fundamentally change the manner in which people shop as well as the structure of the consumer products industry and the retail industry (Alba et al., 1997:38).

The potential of the Internet as a marketing tool stems from benefits such as enormous computing and data storage capacity; availability 24 hours per day, seven days a week; ease and convenience of accessibility from any connected location; absence of physical constraints such as floor space, shelf space, limited product/brand ranges and attribute information (Alba et al., 1997:41); real-time publishing providing automated updating of information, such as availability and inventory levels; cost reductions of up to 25\% (Verity \& Hof in Hoffman \& Novak, 1996:51) in setting up and maintaining an electronic channel, compared to a 'bricks-and-mortar' outlet; increased personal safety, through secured home delivery systems; and reduced consideration sets through electronic search agents (Alba et al., 1997:41).

Provided that the particular character of the Internet is recognised and taken into account when incorporating the Internet in the marketing mix, marketers can use the Internet technology to allow consumers to evaluate a firm's customised offerings, to initiate two-way communication and to make an actual purchase with maximum comfort, convenience and efficiency.

The potential benefits, however, are not being translated into actual sales. In South Africa, although R 341 million was spent on-line in 2003, it accounted for only $0,14 \%$ of total retail expenditure (Middleton, 2004) up from 0,09\% in 2001 (World Wide Worx, 2002).

\section{Barriers to Internet retailing adoption}

There are three main barriers negatively influencing the growth of electronic retailing, namely medium-specific factors, resistance by retailers and consumer behavioural factors (Nelmapius, 2000:17). 


\section{Medium-specific factors}

Some medium-specific factors that might contribute to the slow adoption rate of e-commerce in general will necessarily also contribute to lower e-tailing (electronic retailing). These factors or barriers to electronic commercialisation include screening software used to block out advertising, lack of trust between buyer and seller because of a conflict of interests (compounded by security concerns with transmitting banking information online), privacy concerns of individuals and a lack of measurement standardisation (Nelmapius, 2000:17).

\section{Resistance by retailers}

Alba et al. (1997:45) believe that the threat of CME distribution channels to established retail formats would cause these retail firms, which made a substantial investment to their current format, to adopt a defensive position to radical changes that might threaten this investment. The 'bricks-and-mortar' retailers are also threatened by reduced profit margins because of an increase in price competition.

Manufacturers and marketers who add the Internet to their existing range of distribution channels face the very real possibility of what is known as channel conflict and may face threats such as legal action and refusal to sell a manufacturer's products.

\section{Consumer behavioural factors}

Whilst the objective of marketing is to meet and satisfy target customers' needs and wants consumer behaviour studies how individuals, groups and organisations select, buy, and use products to satisfy those needs and desires (Kotler, 1998:160). According to Popkowski, Sinha and Timmermans (2000:324) consumer behaviour 'depends upon idiosyncratic preferences and socio-economic characteristics that either allow or restrain them from pursuing some of the [buying] options. For example, active search requires a substantial amount of time that households working long hours may not have'.

The Internet retail environment has a unique character, which is substantially different from that of the physical retail outlet (Alba et al., 1997:53) and it is proposed that consumer behaviour in a hypermedia CME will therefore also be different from consumer behaviour in a physical retail environment. The character of the Internet, with somebody sitting in front of an inter-connected computer, in a familiar physical environment, means that most of the decision-making is done in isolation with little or no interaction with others. The Internet retail environment is also a relatively unfamiliar and complex environment exacerbated by the lack of the stimuli of touch, smell and taste as compared to the physical environment. All of these factors together with the natural resistance to change can be expected to further slow down the rate of electronic retailing adoption. The lack of stimuli and realism make it especially important for the Internet retailer to have a proper understanding of consumer decision-making in a virtual environment.
At present the amount of research that has been conducted on consumer behaviour in CME retail is negligible compared to the amount of research conducted in physical retail outlets (Hoffman \& Novak, 1996:52). It is then suggested that this lack of knowledge of consumer behavioural factors in a CME, at present, poses the greatest threat to the adoption and eventual success of the Internet retail channel and as such needs to be researched.

\section{Consumer decision-making in a CME environment}

According to Lamb, Hair, McDaniel, Boshoff and Terblanche (2000:67), a consumer follows a specific decision-making process that starts with recognition of a problem (unsatisfied need or want), to search for information about alternatives, to evaluate the alternatives, to make the purchase and then to engage in post-purchase behaviour that will make them feel either satisfied or dissatisfied with the purchase. In addition the social dimensions of individual factors, social factors and the physical buying situation further influence the decisionmaking process.

We argue that, unlike retailing in a physical environment, an individual commonly conducts Internet retailing in the privacy and comfort of familiar physical surroundings (being either at home or work), but relatively unfamiliar 'virtual' surroundings, for example, making use of a dropdown menu to select a product from an Internet site. The consumer can complete the whole process or break it off at any point if not entirely satisfied with the process, without any social influence from, for example, a sales person. It is therefore suggested that the physical decision-making model be adapted, so as to reflect the unique character of the virtual retail experience. The virtual model has no 'social factors' due to the lack of interaction and this should not be included in the factors that influence the consumer decisionmaking process.

It is proposed therefore that a model of consumer behaviour in an electronic retail environment should exclude a social dimension.

\section{Information search behaviour}

Wilson (in Rowley, 1999:289) identifies three levels of information: information behaviour, information seeking and information search. It is proposed that information search forms part of information seeking, which in turn forms part of information behaviour. Information behaviour is concerned with the way in which individuals and organisations use information for work, education and leisure. Information seeking is concerned with the different methods used to gain access to information resources and information search behaviour is concerned with the interaction between the information user and, in this study, computer-based information systems. 


\section{The economics of information search behaviour}

The concept of scarcity leads to a choice as to which of the unlimited needs an individual typically experiences, are to be satisfied with the limited resources at the individual's disposal. The consumer decision-making process takes place because of the necessity of choice (one cannot purchase all identified alternatives) and therefore these processes take place within an economic context.

The scarce resources include available time and cognitive effort expended in conducting an active search for information regarding products the individual 'needs' to purchase. Stigler (1961: 216), who is cited by many as the pioneer of the economics of information literature, argues that: 'The cost of search, for a consumer, may be taken as approximately proportional to the number of (identified) sellers approached, for the chief cost is time. This cost incurred needs not be equal for all consumers, of course: aside from differences in taste, time will be more valuable to a person with a large income. If the cost of search is equated to its expected marginal return, the optimum amount of search will be found' where search is defined as 'the phenomenon of ascertaining the most favourable price by canvassing various buyers or sellers'.

It is further argued that search costs will affect the extent of search behaviour. These search costs include aspects such as time, out-of-pocket monetary expenses, psychological discomforts, the satisfaction forgone by delaying purchase and the danger of information overload (Engel, Blackwell \& Kollat in Jang, 1996:157). Other factors affecting information search includes: new products' similarity or dissimilarity to categories stored in memory (Ozanne, Brucks \& Grewal in Jang, 1996:158); price paid and quantities purchased (Carlson \& Gieseke in Jang, 1996:157); income, age, education, health status, previous experience, time constraints, presence of children, full-time work and marital status (Jang, 1996:159).

Based on this economic theory, Urbany, Dickson and Kalapurakal (1996:92) propose that, 'consumers also engage in household production and allocate time, money and effort in the production of utility. Leisure activities and various household production activities compete for the limited time that is not spent working, and the household's outputs are constrained by both income and available time (creates time pressure)'. The limits on consumer's time (time pressure), as well as consumer habits, will cause a consumer to change his/her behaviour (involvement), only if the benefits of doing so outweigh the effort needed to switch.

\section{Time pressure}

Time availability can be defined as the amount of time consumers have to educate themselves about a product category and the alternatives that are available, prior to making a decision (Blodgett, Hill \& Stone, 1995:518). Time availability consists of both the time it takes to physically search for information and the time it takes to mentally process that information.
The empirical findings of studies that have investigated the relationship between time pressure and information search behaviour have produced inconclusive results. On the one hand, Sprott and Miyazaki (in Laroche, Saad, Browne, Cleveland \& Kim, 2000:4); Beatty and Smith (1987:84), Moore and Lehman (1980:304), Jang (1996:155), Urbany et al. (1996: 92) and Blodgett et al. (1995:520) all found that as time pressure increases, information search decreases. In other words, there exists an inverse relationship between information search and time pressure. The studies of Kiel and Layton and Newman and Staelin (in Blodgett et al., 1995:519) and Putrevu and Ratchford (1997:463), on the other hand, found no relationship between time pressure and information search.

These conflicting results of the effect of time pressure on consumer behaviour serve as an indication that the relationship between time pressure and consumer behaviour has not been conclusively established in the literature, especially in a CME environment and as such necessitates closer scrutiny.

\section{Involvement as determinant of information search}

Kapferer and Laurent (in Saunders, 1991:80) generically defines involvement is an unobservable state of motivation, arousal or interest. It is evoked by a particular stimulus or situation. It has drive properties: its consequences are types of searching, information processing and decision-making.

Involvement theory is based on the theory of hemispherical lateralisation, which postulates that the human brain consists of two hemispheres (right-brain and left-brain) each of which specialises in a specific information processing process (Du Plessis \& Rousseau, 2003: 257). The left hemisphere is rational, active, realistic and is responsible for cognitive activities such as reading, speaking and attributional information processing, whereas the right-brain is emotional, metaphoric, impulsive and intuitive and is responsible for nonverbal, timeless, pictorial and holistic information (Schiffman \& Kanuk, 1991:210).

Consumer involvement is an important moderator of the amount and type of information processing that is elicited by a persuasive argument (Petty, Cacioppo, \& Schumann, 1983:136). Based on the theory of hemispherical lateralisation, consumers can be classified according to their degree of involvement into either low-involvement or highinvolvement (Schiffman \& Kanuk, 1991:210). Lowinvolvement purchases are purchases that the consumer does not regard as very important, have very little relevance to the consumer, have little perceived risk associated with them and are characterised by little motivation to expend cognitive effort and time on processing information associated with a message. According to Park and Mittal (in Saunders, 1991:73) 'when a subject's involvement is low his/her attention focus lacks direction and the level of processing is superficial, revealing different patterns in schema activation (or imagery retrieval) and information organisation from those at a high level of involvement. Low involvement subjects are not likely to invoke a relevant schema (or image) in evaluating a commercial; if a schema is invoked, subjects are more inclined to use schema 
information in simplified ways, and the information contained in the commercial may not be processed and organised in a coherent manner'.

High-involvement conditions cause the experience of a high level of motivation, arousal or interest that causes greater searching, information processing and decision-making by individuals. The lack of cognitive effort during lowinvolvement processing precludes the forming of a strong long-term memory link with the associated message, which might lead a consumer to become disassociated from the message. Under high-involvement conditions there exists a strong link between the message and long-term memory, which means attitudes formed under high involvement conditions should remain stable over time (Sengupta, Goodstein \& Boninger, 1997:352).

The objective of this study was to consider the consumer behaviour (the interplay between consumer involvement, time pressure and time taken per unit purchased) of Internet shoppers in a three-dimensional electronic retail shopping environment.

\section{Three-dimensional shopping}

\section{Familiarity}

For many shoppers, switching from a traditional physical retail outlet to a non-traditional two-dimensional electronic retail outlet will be a radical departure from their acquired habit, as electronic retailing is extremely unfamiliar to most consumers.

In a study conducted by Veryzer and Hutchinson (1998:376), it was found that moderate familiarity, when displaying products, is preferred to both extreme familiarity and extreme unfamiliarity. It is proposed, therefore, that a three-dimensional electronic retail outlet (moderate familiarity as it resembles at least partially the 'real world') will provide higher utility to the consumer than either a physical retail outlet (extreme familiarity) or a twodimensional electronic retail outlet (extreme unfamiliarity). In a retail context Burke (who created a simulation of a three-dimensional retail shop in order to test market product, packaging and other design alternatives) argues that: 'Threedimensional shop displays work best when they leverage the knowledge that consumers already have about how to shop in the physical store. Think about a grocery store: a typical supermarket carries over 30,000 different items. Consumers know a tremendous amount of information about shopping there, related to the store layout, package appearance, where to find things. By creating an electronic model of the physical store, customers can use their knowledge for easy transition from the physical store to online shopping' (Burke in Englert, 1999).

\section{Search behaviour and visualisation}

Search processes in an electronic environment could also be regarded as human information processing in which there are visual perception and decision-making processes and the processes in working memory. Through a visual search process the users examine the items (in this case) on a website (perception process).

The decision-making process consists of aspects such as visualising the entire website structure, keeping track of the paths chosen, avoiding getting lost and determining which paths to choose next. The whole process is deemed to take place in working memory. Visualisation requires the mental rotation of spatial configuration in short-term memory. From this it can be concluded that an individual's visualisation capability will have a significant influence on information search processes and that individuals with low visualisation ability will be appreciably less effective in information retrieval. A key factor in assisting individuals with low visualisation ability is to reduce the working memory load by eliminating the need to visualise information of an embedded task. Working memory load can be reduced by using colour graphs (Zhang \& Salvendy, 2001:79) and thus reducing cognitive burden, by shifting some of the effort to visual perception.

To summarise: for many consumers switching from a physical retail outlet to a traditional two-dimensional electronic retail outlet (consisting of two dimensional drop down menus in order to select products) will be a radical departure from their acquired habit, as it is extremely unfamiliar to most consumers (Veryzer \& Hutchinson, 1998:376). It was thus argued that a three-dimensional electronic retail outlet (moderate familiarity) would provide a higher level of utility to the consumer than either a physical retail outlet (extreme familiarity) or a traditional two-dimensional electronic retail outlet such as those offered by Pick n Pay at present (extreme unfamiliarity).

In this study colour photographs were used to represent products in a three-dimensional retail environment in order to reduce the complexity of the visual search environment, and to provide a moderately familiar shopping environment.

One of the key benefits that e-commerce offers is the customisation offered to consumers. Under certain circumstances market offerings can be exactly customised to the needs of each individual consumer. A three-dimensional retail outlet will provide the required telepresence, realism, reduced cognitive effort and moderately familiar environment preferred by some consumers.

The potential utility (through cost, time and cognitive search savings) that an electronic retail environment offers the consumer, enhanced by a moderately familiar threedimensional retail environment, should provide the optimum environment for future retailing. It cannot be assumed, however, that consumer behaviour in a physical retail environment will be the same as consumer behaviour in an electronic retail environment and necessitates research to assess the differences between physical retail consumer behaviour and electronic retail consumer behaviour.

There is a substantial body of research on the traditional two-dimensional electronic environment, including aspects such as consumer decision-making in the online shopping environment (Haubl \& Trifts, 2000); marketing in computer mediated environments (Hoffman \& Novak, 1996); 
consumer, retailer and manufacturer incentives to participate in interactive home shopping (Alba et al., 1997); external information search in in-home shopping situations (Sundaram \& Taylor, 1998) and the implications of visualisation ability for web information search tasks (Zhang \& Salvendy, 2001).

At present however, the amount of research on consumer behaviour in electronic retail designs and atmospherics in a simulated three-dimensional environment seems to be limited to anecdotal evidence with little or no empirical substantiation. According to Schneiderman in Zhang \& Salvendy (2001:76) 'It will take a decade until sufficient experience, experimentation and hypothesis testing clarifies design issues' in an electronic retail environment. After an extensive literature study search, it seems that the only scholarly research on virtual three-dimensional retail outlets is that performed by Burke (in Englert, 1999). His work is limited, however, to the test marketing of different product designs and does not address consumer behaviour constructs.

\section{Objectives of the study}

In a study conducted by Sundaram and Taylor (1998:440) a complete model of information behaviour in a twodimensional electronic environment was investigated. In their study the following variables that influence the information search effort of Internet shoppers were examined: their perceptions of risk, knowledge, purchasing experience, involvement, time pressure, perceived benefits of search, awareness of sources of information, ease of access to sources of information, education, income and age.

Sundaram and Taylor (1998:440) concluded that perceived risk increases both consumers' search effort and perceived benefits of search, which suggests that in-home shoppers engaged in greater information search, because of the belief that extended search would result in better deals in terms of price and quality.

Contrary to expectations, product knowledge was found to be positively related to search effort. In other words, consumers with greater knowledge were able to process information more extensively and this motivates greater information search, whereas less knowledgeable consumers do not have the same memory structure and, as a result, find searching overwhelming and are therefore less motivated to search. Contrary to expectations, purchasing experience and knowledge failed to reduce the perceptions of risk and only income was found to be negatively related to risk. Time pressure was found to be inversely related to the in-home shoppers' search effort. Time pressure thus has a twofold influence on information search. Firstly, time pressure may cause consumers to rely on existing knowledge and not to actively search for information and secondly, that under time pressure, consumers may limit their information search to a few sources that are easily accessible. Another unexpected finding was that there is no direct positive relationship between involvement and search effort, but only an indirect one. Awareness of sources and access to sources were both found to have a significant positive impact on the search effort. These findings highlight the importance for marketers to formulate their marketing communication in such a way as to increase access to information. In general it was found that most of the in-home shopping behaviour closely resembles that of in-store shopping. Sundaram and Taylor (1998) suggested that the information search behaviour models of in-store shopping can be extended to interactive home shopping.

The objective of this study was to investigate a sub-set of the variables that influence the information search effort identified in the Sundaram and Taylor (1998) study. Specifically the effect different types of information displays (product and price information) and time pressure in particular has on consumer involvement in different electronic retail environments were investigated $(\mathrm{H} 1-\mathrm{H} 4)$. The empirical results should provide tentative guidelines for an optimum virtual retail design strategy when utilising the Internet as a retailing medium.

The dependent variables to be analysed are consumer involvement in the shopping process (H1) and actual time spent per unit purchased (H2). The independent variable is time pressure as experienced in four different shopping environments (implying four sub-hypotheses). Time pressure can thus be seen as an intervening variable rather than an independent variable.

These two hypotheses (see Figure 1) are then considered in four different shopping environments. In other words, the influence of time pressure (independent variable) on consumer involvement and time spent shopping in a CME is studied in four different CME environments by manipulating the availability of information (price information, product information and product displays) on the four different Web sites that represented the four different 'shops'.

Hypotheses 3 and 4 addressed the same dependent variables (consumer involvement and time taken per unit purchased) but did not include time pressure as 'intervening variable' as shown in Figure 1. In other words, the consumer involvement and time taken per unit purchased of online shoppers were assessed without putting them under any time pressure to complete their shopping.

\section{The measurements}

Consumer involvement is operationalised as the effort a buyer invests in the search, evaluation and decision-making processes when making a purchase (Lamb et al., 2000:72). The extent of information search behaviour is operationalised as the number of pieces of information acquired as suggested by Moore and Lehman (1980:297) and Schaninger and Sciglimpaglia (in Laroche et al., 2000:6). 


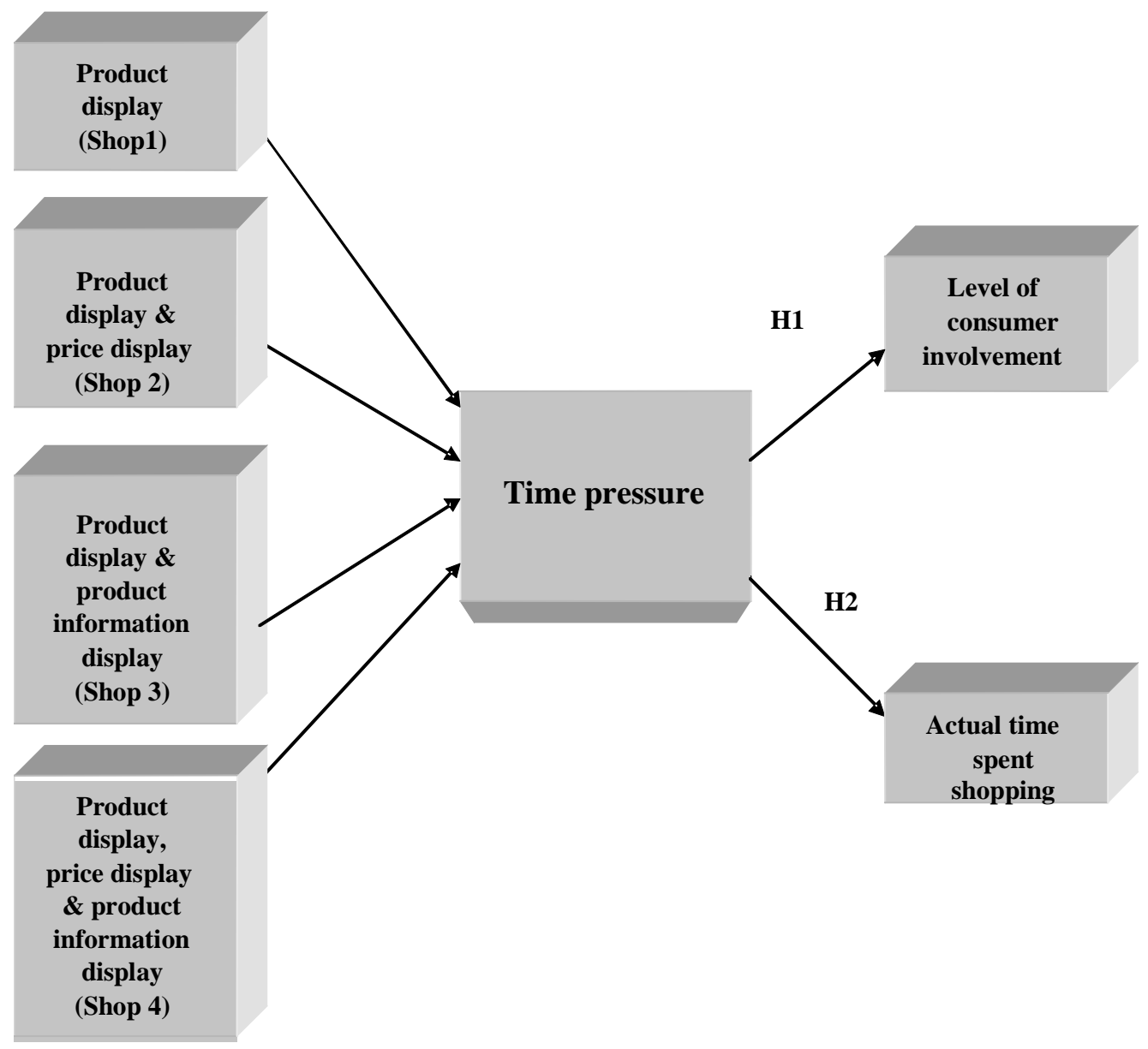

Figure 1: The hypotheses

Actual time spent per unit purchased $\left(T_{a}\right)$ is determined by dividing the time used to purchase these items $\left(T_{u}\right)$ by the number of articles purchased $\left(\mathrm{N}_{\mathrm{a}}\right)$.

$$
\mathrm{T}_{\mathrm{a}}=\frac{\mathrm{T}_{\mathrm{u}}}{\mathrm{N}_{\mathrm{a}}}
$$

Time pressure relates to the number of articles that had to be purchased in a given amount of time. In other words, the greater the number of articles to be purchased in a given amount of time, the higher the time pressure.

For the purpose of this study, price display refers to a threedimensional, electronic retail environment in which the prices of products are displayed on the products and are therefore immediately visible. Information display refers to a three-dimensional, electronic retail environment in which information relating to the product is displayed on the product and is therefore immediately visible.

\section{Hypotheses}

Four hypotheses were considered in this study. The first hypothesis is:
H1: There is a negative relationship between shopping time pressure and the level of shopper involvement

In order to further investigate this hypothesised relationship it was also tested in four different shopping environments, namely (a) a shopping environment with the product displayed (pictures) but without price information or product information (shop 1); (b) a shopping environment with product displays as well as price information but no product information (shop 2); (c) a shopping environment with product displays and product information but no price information (shop 3); (d) a shopping environment with product displays as well as both price information and product information (shop 4). As a result the following subhypotheses were considered:

- $\quad$ H1a: There is a negative relationship between shopping time pressure and the level of shopper involvement without price or product information being available

- H1b: There is a negative relationship between shopping time pressure and the level of shopper involvement with only price information being available 
- $\quad$ H1c: There is a negative relationship between shopping time pressure and the level of shopper involvement with only product information being available

- H1d: There is a negative relationship between shopping time pressure and the level of shopper involvement with both price and product information being available

The second hypothesis to be addressed was:

H2: There is a negative relationship between shopping time pressure and actual time spent per unit purchased

As with the previous main hypothesis the manipulation of price and product information displays allowed the testing of the following sub-hypotheses:

- $\quad$ H2a: There is a negative relationship between shopping time pressure and actual time spent per unit purchased without price or product information being available

- H2b: There is a negative relationship between shopping time pressure and actual time spent per unit purchased with only price information being available

- $\quad$ H2c: There is a negative relationship between shopping time pressure and actual time spent per unit purchased with only product information being available

- H2d: There is a negative relationship between shopping time pressure and actual time spent per unit purchased with both price and product information being available

Hypotheses 3 and 4 were similar but excluded the influence of time pressure. Thus:

H3: There is no relationship between information availability (product and price information) and consumer involvement in a CME environment

H4: There is no relationship between information availability (product and price information) and actual time spent per unit purchased

As previously the nature and amount of information that the online shoppers were exposed to were manipulated by allowing them to shop in four different CME 'shops'.

\section{Methodology}

A non-probability convenience sample of 120 subjects was drawn from the student population of the then University of Port Elizabeth. In a study conducted by Briggs, Balthazard, and Dennis (1994:11), it was found that subjects are 'good or even conservative surrogates' for evaluating technology, if the concept to be researched falls within their interest scope. The present research of virtual retailing falls within the interest field of all subjects (all subjects indicated spending at least one hour per week shopping in a physical retail outlet); therefore they are acceptable surrogates for the South African shopper.
The data collection took the form of an experiment/observation study. In co-operation with the Department of Computer Science and Information Systems of the then University of Port Elizabeth, a threedimensional, virtual storefront software programme was developed, called Virtual Shopper. This software package was used to create the virtual storefronts that were used in the experiments. In a virtual retail outlet, as stated above, consumers are trying to apply learned physical retail behaviour in the virtual environment. Therefore, a threedimensional interface was used in order to give another dimension of reality and thus better test behavioural constructs in this reality. In order to enhance this reality even further, all products were represented by photographs. The Virtual Shopper programme provided a feature that allowed the respondents' simulated shopping in the different shops to be recorded and saved as a text file (ASCII file), which provided the raw data to be analysed for this study.

The experiment consisted of three phases. Phase one was a pilot study to assess the validity of the constructs of high time pressure and low time pressure. Phase two consisted of a pre-test to validate the findings of the pilot study. Phase three was the main experiment to collect the data to test the stated hypothesis.

\section{The sample}

An analysis of the demographic profile of the 120 subjects who made up the sample revealed that the gender distribution of the sample is fairly even between male $(47,5 \%)$ and female (52,5\%). English-speaking subjects (49,2\%) and Afrikaans-speaking subjects (49,2\%) dominate the sample and most subjects were older than 25 (46,7\%).

\section{The pilot study}

As previously mentioned, no study has yet been conducted regarding consumer behaviour in a three-dimensional retail environment. It was therefore necessary to conduct a pilot study to confirm what constitutes the construct of time pressure and specifically what subjects would regard as high, medium and low time pressure. The pilot study also permitted an assessment of the Virtual Shopper software.

The pilot study consisted of 12 subjects (randomly selected from the general student population of the then University of Port Elizabeth) with varying degrees of computer proficiency. Four different shops were created (shop 1, 2, 3 and 4) representing the four types of displays. Each respondent was given the same list of 12 products and given instructions as to the procedure for making a purchase. Subjects were told that they were required to purchase three products from each of the four virtual shops as indicated on the shopping list they were given. They were also informed that they were being timed, but that there was no time limit to complete the shopping task and that no further help would be provided. 


\section{The pre-test}

The estimations of what constitutes high time pressure and low time pressure, as based on the average time established in the pilot test, had to be empirically validated by means of a pre-test. For this purpose eight shops were created for the pre-test to ensure that subjects were exposed to buying the products in a unique display and shop layout and to reduce any history effect (Zikmund, 1994:257) that might occur.

The results indicated that where subjects were expected to purchase 5 products in 1 minute, on average only $62 \%$ of the expected 5 products could be purchased. In other words, on average only 3 of the required 5 products could be purchased in 1 minute. Of the 20 subjects who participated in the pre-test, not one could purchase the required 10 products ( 5 per shop $\times 2$ shops) in the allocated two minutes (1 minute per shop x 2 shops). The questionnaire results indicate that 9 subjects strongly disagreed, 3 subjects somewhat disagreed, 7 subjects disagreed and one respondent was neutral to the statement that: 'using shopping list 1, I had enough time to do my shopping'. From these results it was reasonable to infer that to purchase 5 products in one minute in the Virtual shopper threedimensional retail environment represents a high time pressure situation.

The results further indicated that when they were expected to purchase 3 products in 2 minutes, all of the subjects were able to purchase the required 3 products in the allocated two minutes. The questionnaire results indicated that 17 subjects strongly agreed and 3 subjects somewhat agreed to the statement that: 'using Shopping list 2, I had enough time to do my shopping'. From these results it was reasonable to infer that to purchase 3 products in 2 minutes in the Virtual Shopper three-dimensional retail environment represents a low time pressure situation.

\section{The main experiment}

The main experiment attempted to assess the impact/influence of time pressure on the level of shopper involvement and actual time taken to purchase a product in different display environments in a three-dimensional retail outlet.

Five shops were created for the main experiment. One shop was used to familiarise subjects to the task at hand. The five different shops were labelled shop 1 , shop 2, shop 3 and shop 4 and 'example'. In shop 1, all products were displayed without product prices or product information immediately visible. In shop 2, all products were displayed with only product prices immediately visible. In shop 3, all products were displayed with only product information immediately visible. In shop 4, all products were displayed with both product prices and product information immediately visible. The 'example' shop contained shelves from all four display environments combined.

All the products belonging to a product group were grouped together on a shelf in each of the five shops. Products in a product group were randomly assigned a position on the shelf, for each of the four shops (1 - 4) and each shelf was assigned a different position in each of the four $(1-4)$ shops, but using the same layout for all the different shops. The example shop contained randomly selected products of all four display types arranged as isolated shelves in the shop and did not resemble any of the other shops used in the main study.

The main study consisted of 120 subjects that were randomly divided into four groups, representing the between-group manipulation of the independent variable. The groups were labelled group A, group B, group C and group D:

- Group A was given a list of 20 products, which had to be purchased from four different shops within 4 minutes (1 minute per shop). Group A, based on the pre-test, can be described as the high time pressure group.

- Group B was given a list of 20 products, which had to be purchased from four different shops within 8 minutes ( 2 minutes per shop). Based on the pre-test, this group is the medium time pressure group.

- $\quad$ Group C was given a list of 12 products, which had to be purchased from four different shops within 4 minutes (1 minute per shop). Group C, based on the pre-test, may be described as a medium time pressure group.

- Group D was given a list of 12 products, which had to be purchased from four different shops within 8 minutes (2 minutes per shop). Based on the pre-test, this group is the low time pressure group.

All four groups had to purchase products from four different shops (shop 1-4), which served to expose the subjects to all four of the display environments and as such represent the within-group manipulation of the independent variable.

All the subjects were required to complete three questionnaires following the 'shopping excursion'. The first questionnaire was a computer proficiency questionnaire. Streicher et al. (as cited and used in Van Greunen, 2002:71) claim that human-computer interaction capacities and skills 'have tremendous individual differences'. In order to control for the differences in computer proficiency across the different subject groups, a computer proficiency questionnaire, developed by Streicher et al. (as cited and used in Van Greunen, 2002:71), was used to assess the computer proficiency of the individual subjects participating in the study. The questionnaire consists of 23 questions using a 5-point Likert scale (one indicating low proficiency and five high proficiency) to assess the user's self-perceived ability to work with computers, attitude towards computers, previous experience with computers and contact with other related technology. The scores of the 23 questions were summed for each respondent and then the scores of the respondents in the different groups were totalled resulting in a computer proficiency score for each subject.

The four experimental groups were almost equal (on average all within four points from one another) with regard 
to computer proficiency level and the groups were also very similar regarding the standard deviation with the range of the four groups being only 2.3 points. The results indicate that computer proficiency amongst the groups of subjects participating in the main study should therefore not influence their responses (has been controlled for).

The second questionnaire was a demographic questionnaire to collect demographic information and the third questionnaire was a brand recognition questionnaire, which served as a qualifying questionnaire to control for brand recognition. Only subjects who answered all the qualifying questions correctly were included in the study. All 120 subjects used in the study answered all the qualifying questions correctly.

\section{The empirical results}

The first hypothesis stated that there is a negative relationship between shopping time pressure and the level of shopper involvement (note that time pressure is the independent variable and not available shopping time).

Table 1: Correlation analysis between time pressure and consumer involvement

\begin{tabular}{|c|c|c|c|c|c|}
\hline \multirow{2}{*}{$\begin{array}{c}\text { Dependent } \\
\text { Variable }\end{array}$} & & \multicolumn{4}{|c|}{ Independent variable: Time pressure } \\
\hline & & $\begin{array}{l}\text { Time pressure without } \\
\text { price or product } \\
\text { information } \\
\text { (Shop 1) }\end{array}$ & $\begin{array}{l}\text { Time pressure } \\
\text { with only price } \\
\text { information } \\
\text { (Shop 2) }\end{array}$ & $\begin{array}{c}\text { Time pressure with } \\
\text { only product } \\
\text { information } \\
\text { (Shop 3) }\end{array}$ & $\begin{array}{l}\text { Time pressure with both } \\
\text { price and product } \\
\text { information } \\
\text { (Shop 4) }\end{array}$ \\
\hline \multirow[t]{3}{*}{ Involvement } & Pearson Correlation &,$- 200 *$ & & & \\
\hline & Sig. (2-tailed) & ,029 & & & \\
\hline & $\mathrm{n}$ & 120 & & & \\
\hline \multirow[t]{3}{*}{ Involvement } & Pearson Correlation & &,$- 262 * *$ & & \\
\hline & \begin{tabular}{|l|} 
Sig. (2-tailed) \\
\end{tabular} & &, 004 & & \\
\hline & $\mathrm{n}$ & & 120 & & \\
\hline \multirow[t]{3}{*}{ Involvement } & Pearson Correlation & & &,$- 345 * * *$ & \\
\hline & \begin{tabular}{|l|} 
Sig. (2-tailed) \\
\end{tabular} & & &, 000 & \\
\hline & $\mathrm{n}$ & & & 120 & \\
\hline \multirow[t]{3}{*}{ Involvement } & Pearson Correlation & & & &,- 052 \\
\hline & Sig. (2-tailed) & & & &, 571 \\
\hline & $\mathrm{n}$ & & & & 120 \\
\hline
\end{tabular}

* Correlation is significant at the 0,05 level

** Correlation is significant at the 0,01 level

*** Correlation is significant at the 0,001 level

The empirical results shown in Table 1 indicate that there is a negative correlation $(-2,00)$ between shopper involvement and shopping time pressure in a shopping environment (a 'shop') without price or product information displays ( $\mathrm{p}<$ $0,05)$. When only price information is displayed the negative correlation is $-0,262$ ( $p<0,01)$. When only product information is displayed the negative correlation is $-0,345$ ( $\mathrm{p}<0,001) . \mathrm{H} 1$ is therefore accepted with respect to electronic shopping environments ('shops') without price and information displays (H1a), where only price (H1b) or only product information is displayed (H1c). In other words, the higher the time pressure, the lower the shopping involvement except when both price and product information are available to the Internet shopper.

The second hypothesis tested was that there is a negative relationship between shopping time pressure and actual time spent per unit purchased.

The empirical results shown in Table 2 indicate that there is no significant correlation between time pressure and actual time spent to purchase a product irrespective of the shopping environment in which the shopper finds himself. In other words, in a CME environment time pressure does not influence the actual time taken to buy individual units of a product. H2 is therefore rejected.

\section{The ANOVA results}

A second objective was to determine whether exposure to different electronic retail environments (shops 1 to 4 ) influences the shopper involvement without time pressure being modelled as an intervening variable (see Figure 1). A third objective was to determine whether exposure to different electronic retail environments (shops 1 to 4) would influence the actual time taken to purchase products without time being modelled as an intervening variable. In other words, the different shops were now regarded as the independent variables and shopper involvement was modelled as dependent variable.

As the independent variable was now scaled using nominal data (type of shop) and the independent variables were ordinally-scaled (shopper involvement in the one case and actual time spent shopping per unit in the other case) an Analysis of Variance (ANOVA) was used to address Hypotheses 3 and 4. 
Table 2: Correlation analyses between time pressure and actual time taken per unit purchased

\begin{tabular}{|c|c|c|c|c|c|}
\hline \multirow{2}{*}{ Dependent variable } & & \multicolumn{4}{|c|}{ Independent variable: Time pressure } \\
\hline & & $\begin{array}{l}\text { Time pressure without } \\
\text { price or product } \\
\text { information } \\
\text { (Shop 1) }\end{array}$ & $\begin{array}{l}\text { Time pressure } \\
\text { with only price } \\
\text { information } \\
\text { (Shop 2) }\end{array}$ & \begin{tabular}{|c|} 
Time pressure with \\
only product \\
information \\
(Shop 3)
\end{tabular} & $\begin{array}{l}\text { Time pressure with both } \\
\text { price and product } \\
\text { information } \\
\text { (Shop 4) }\end{array}$ \\
\hline \multirow[t]{3}{*}{ Actual time taken } & Pearson Correlation & ,109 & & & \\
\hline & Sig. (2-tailed) & ,236 & & & \\
\hline & $\mathrm{n}$ & 120 & & & \\
\hline \multirow[t]{3}{*}{ Actual time taken } & Pearson Correlation & & ,010 & & \\
\hline & Sig. (2-tailed) & & 918 & & \\
\hline & $\mathrm{n}$ & & 120 & & \\
\hline \multirow[t]{3}{*}{ Actual time taken } & Pearson Correlation & & &,- 058 & \\
\hline & Sig. (2-tailed) & & &, 528 & \\
\hline & $\mathrm{n}$ & & & 120 & \\
\hline \multirow[t]{3}{*}{ Actual time taken } & Pearson Correlation & & & &,- 007 \\
\hline & Sig. (2-tailed) & & & & ,943 \\
\hline & $\mathrm{n}$ & & & & 120 \\
\hline
\end{tabular}

Table 3: ANOVA results with shopper involvement as dependent variable

\begin{tabular}{|c|c|c|c|c|c|c|c|}
\hline & & Sum of Squares & df & Mean Square & $\mathbf{F}$ & & Sig. \\
\hline \multirow{3}{*}{$\begin{array}{l}\text { Involvement without price } \\
\text { or product information }\end{array}$} & Between Groups & 3,483 & 2 & 1,742 & & 1,159 & ,317 \\
\hline & Within Groups & 175,817 & 117 & 1,503 & & & \\
\hline & Total & 179,300 & 119 & & & & \\
\hline \multirow{3}{*}{$\begin{array}{l}\text { Involvement with only } \\
\text { price information }\end{array}$} & Between Groups & 2,825 & 2 & 1,412 & & 3,032 & 052 \\
\hline & Within Groups & 54,500 & 117 & ,466 & & & \\
\hline & Total & 57,325 & 119 & & & & \\
\hline \multirow{3}{*}{$\begin{array}{l}\text { Involvement with only } \\
\text { product information }\end{array}$} & Between Groups & 2,700 & 2 & 1,350 & & 1,182 & ,310 \\
\hline & Within Groups & 133,667 & 117 & 1,142 & & & \\
\hline & Total & 136,367 & 119 & & & & \\
\hline \multirow{3}{*}{$\begin{array}{l}\text { Involvement with both } \\
\text { price and product info }\end{array}$} & Between Groups & 1,200 & 2 & 600 & & ,869 & 422 \\
\hline & Within Groups & 80,800 & 117 & ,691 & & & \\
\hline & Total & 82,000 & 119 & & & & \\
\hline
\end{tabular}

Table 4: ANOVA results with shopping time as dependent variable

\begin{tabular}{|c|c|c|c|c|c|c|}
\hline Time without price or & Between Groups & 41,858 & 2 & 20,929 & ,569 & ,568 \\
\hline & Within Groups & 4306,326 & 117 & 36,806 & & \\
\hline & Total & 4348,185 & 119 & & & \\
\hline \multirow{3}{*}{$\begin{array}{l}\text { Time with only price } \\
\text { information }\end{array}$} & Between Groups & 4,999 & 2 & 2,500 & ,059 & 942 \\
\hline & Within Groups & 4935,487 & 117 & 42,184 & & \\
\hline & Total & 4940,487 & 119 & & & \\
\hline \multirow{3}{*}{$\begin{array}{l}\text { Time with only product } \\
\text { information }\end{array}$} & Between Groups & 85,992 & 2 & 42,996 & ,618 & ,541 \\
\hline & Within Groups & 8139,688 & 117 & 69,570 & & \\
\hline & Total & 8225,680 & 119 & & & \\
\hline \multirow{3}{*}{$\begin{array}{l}\text { Time with both price } \\
\text { and product info }\end{array}$} & Between Groups & 4,036 & 2 & 2,018 & ,025 & 975 \\
\hline & Within Groups & 9398,799 & 117 & 80,332 & & \\
\hline & Total & 9402,835 & 119 & & & \\
\hline
\end{tabular}


The ANOVA results as shown in Table 3 show that, at the $5 \%$ level of significance, there is no relationship $(p>0,05)$ between the type of information that online shopper are exposed to (in shops $1-4$ ) and the level of their shopper involvement.

The results in Table 4 show that there is no relationship ( $\mathrm{p}>$ $0,05)$ between the actual time spent per unit purchased and the electronic retail environment (different types of information available) in which the unit was purchased.

\section{Summary of empirical results}

The correlation analysis shows that there is a negative relationship between shopping time pressure, on the one hand, and a shopping environment without price and product information displays $(\mathrm{p}<0,05)$; a shopping environment with only price displays $(\mathrm{p}<0,01)$ and a shopping environment with only product information displays $(\mathrm{p}<$ $0,001)$. There is, however, no relationship between time pressure and involvement when both price and product information are available. The ANOVA indicates that there is no relationship between the level of shopper involvement nor the time taken to shop in a CME environment irrespective of the type of information available to the online shopper.

\section{Discussion}

The Internet, as retail outlet, is substantially different in nature and functioning as compared to a physical retail outlet, the greatest difference being the limited stimuli, the lack of social interaction, greater access to expanded global markets, the absence of shop assistants, the ability to offer complete customisation at an individual level and the immense computing power at the disposal of marketers and consumers.

The differences between the physical and virtual environments (despite the findings of Sundaram \& Taylor, 1998:440) will cause a substantial difference in consumer behaviour in a virtual environment, as compared to the consumer behaviour in a physical retail environment.

The three-dimensional virtual retail environment is unique and as such will be unfamiliar to all users. This may cause users to experience the Virtual Shopper as an extremely unfamiliar environment until such time as a minimum level of learning has taken place, which will cause the Virtual Shopper experience to be experienced as a moderately familiar environment. If the research subjects experienced the shopping as extremely unfamiliar, their behaviour might not be indicative of general shopping behaviour, but shopping behaviour in an extremely unfamiliar environment. The experience of the Virtual Shopper environment as extremely unfamiliar may negatively influence the external validity of the research results. Virtual Shopper, as a first attempt at developing a new to the world, three-dimensional, retail software package, may not consist of an optimum design for consumer use and as such might adversely influence the reliability of the research results.

\section{Recommendations}

The virtual environment has already impacted significantly on the way people communicate and how business is conducted and the rate of change can be expected to accelerate in the future. In order for marketers to individualise offerings (one of the most important capabilities of the Internet), they need to understand consumer behaviour within the unique and unfamiliar virtual environment as opposed to the physical environment.

The variables examined in the current study represent only a sub-set of the complete consumer behaviour model and the high number of unsupported hypotheses of the current study cannot be seen as providing conclusive proof that there is no difference between consumer behaviour in a virtual environment as opposed to consumer behaviour in a physical retail outlet. It is therefore suggested that further studies are needed to test the consumer behaviour model as a whole.

\section{References}

Alba, J., Lynch, J., Weitz, B., Janiszewski, C., Lutz, R., Sawyer, A. \& Wood, S. 1997. 'Interactive home shopping: Consumer, retailer and manufacturer incentives to participate in electronic marketplaces', Journal of Marketing, 61:38-53.

Beatty, S.E. \& Smith, S.M. 1987. 'External search effort: An investigation across several product categories', Journal of Consumer Research, 14:83-95.

Blodgett, J.G., Hill, D.J. \& Stone, G. 1995. 'A model of the determinants of retail search', Advances in Consumer Research, 22:518-524.

Bosch, J.K. 1982. 'An empirical investigation of the goal structure of firms listed on the Johannesburg Stock Exchange: A Comparative study', South African Journal of Business Management, 23(2):76-88.

Borchard, W. G. 1999. 'eCommerce for South African retail companies'. [online]

URL:http://www.itweb.co.za/sections/techforum/1999/9901 051107.asp. Accessed 5 January 1999.

Briggs, R.O., Balthazard, P.A. \& Dennis, A.R. 1994. 'Graduate business students as surrogates for executives in the evaluation of technology', Journal of End User Computing, 8(4):11-17.

Du Plessis, P.J. \& Rousseau, G.G. 2003. Buyer behaviour. $3^{\text {rd }}$ Edition. Cape Town: Oxford.

Englert, L. 1999. 'Virtual shopping adventures'. [online] URL: http://www.indiana.edu/ rcapub/v22n2/p30 html. Accessed 14 February 2002.

Haubl, G. \& Trifts, V. 2000. 'Consumer decision making in online shopping environments: The effects of interactivity decision aids', Marketing Science, 19:4-33. 
Hoffman, D.L. \& Novak, T.P. 1996. 'Marketing in hypermedia computer-mediated environments: Conceptual foundations', Journal of Marketing, 60: 50-68.

Jang, Y.G. 1996. 'Determinants of information search behaviour: The case of savings and borrowing decisions', Consumer Interest Annual, 42:155-164.

Kotler, P. 1998. Marketing management. New Jersey: Prentice-Hall.

Lamb, C.W., Hair, J.F., McDaniel, C., Boshoff, C. \& Terblanche, N.S. 2000. Marketing: A South African perspective. Cape Town: Oxford.

Laroche, M., Saad, G., Browne, E., Cleveland, M. \& Kim, C. 2000. 'Determinants of in-store information search strategies pertaining to a Christmas gift purchase', Canadian Journal of Administrative Sciences, 17: 1-20.

Moore, W.L. \& Lehman, D.R. 1980. 'Individual differences in search behaviour for a nondurable', Journal of consumer research, 7:296-307.

Middleton, J. 2004. 'Online shopping is poised for growth', Bizz-Community Electronic Newsletter, 18 March 2004. [online] URL: www.biz-community.com

Nelmapius, A.H. 2000. 'Guidelines for the use of the Internet as marketing communication medium'. Unpublished Honours dissertation, Nelson Mandela Metropolitan University, Port Elizabeth.

Petty, R.E., Cacioppo, J.T. \& Schumann, D. 1983. 'Central and peripheral routes to advertising effectiveness: The moderating role of involvement', Journal of consumer research, 10:135-146.

Popkowski, P.T.L., Sinha, A. \& Timmermans, H.J.P. 2000. 'Consumer store choice dynamics: An analysis of the competitive market structure for grocery stores', Journal of retailing, 76: 323-346.

Putrevu, S. \& Ratchford, B.T. 1997. 'A model of search behaviour with an application to grocery shopping', Journal of retailing, 73:463-486.

Rowley, J. 1999. 'Towards a consumer perspective on information behaviour research', Information services \& use, 19: 289-299.

Saunders, S.R. 1991. 'The validity of the low-involvement consumer decision-making perspective in a fast moving consumer goods environment'. Unpublished $\mathrm{PhD}$ thesis, Nelson Mandela Metropolitan University, Port Elizabeth.

Schiffman, L.G. \& Kanuk, L.L. 1991. Consumer behaviour. New Jersey: Prentice Hall.
Sengupta, J., Goodstein, R.C. \& Boninger, D.S. 1997. 'All cues are not created equal: Obtaining attitude persistence under low-involvement conditions', Journal of consumer research, 23:351-361.

Stigler, G.J. 1961. 'The economics of information', The Journal of Political Economy, 69:213-225.

Sundaram, D.S. \& Taylor, R.D. 1998. 'An investigation of external search effort: Replication in in-home shopping situations', Advances in Consumer Research, 25:440-445.

Urbany, J.E., Dickson, P.R. \& Kalapurakal, R. 1996. 'Price search in the retail grocery market', Journal of marketing, 60: $91-104$.

Van Greunen, D. 2002. 'Formal usability testing of interactive educational software: a case study approach'. Unpublished MA thesis, Nelson Mandela Metropolitan University, Port Elizabeth.

Veryzer R.W. \& Hutchinson J.W. 1998. 'The influence of unity and prototypicality on aesthetic responses to new product designs', Journal of Consumer Research, 24:374394.

World Wide Worx. 2002. 'The Goldstuck report: Internet access in South Africa, 2002'. [online] URL: http://theworx.biz/access02 htm. Accessed 31 May 2002.

Zhang, H. \& Salvendy, G. 2001. 'The implications of visualisation ability and structure preview design for web information search tasks', International Journal of Humancomputer Interaction, 13:75-96.

Zikmund, W.G. 1994. Business research methods. Fort Worth: Dryden. 
